\title{
Spatiotemporal distribution of coastal and oceanic Atlantic cod Gadus morhua sub-groups after escape from a farm
}

\author{
Ingebrigt Uglem ${ }^{1, *}$, Pål Arne Bjørn ${ }^{2}$, Hiromichi Mitamura ${ }^{3}$, Rune Nilsen ${ }^{2}$ \\ ${ }^{1}$ Norwegian Institute of Nature Research, Tungasletta 2, 7485 Trondheim, Norway \\ ${ }^{2}$ Nofima Marin, Muninbakken 9-13, PO Box 6122, 9291 Tromsø, Norway \\ ${ }^{3}$ Graduate School of Informatics, Kyoto University, Kyoto 606-8501, Japan
}

\begin{abstract}
Little is known about how escaped farmed Atlantic cod Gadus morhua L. affect the environment, but the potential for negative ecological consequences might be significant. In this study, the movements of adult farmed north-east Arctic cod (NEAC) and Norwegian coastal cod (NCC) were mapped after a simulated escape from an aquaculture farm to evaluate if post-escape movements and potential for recapture differs between these 2 genotypes. There was no major difference between NEAC and NCC equipped with acoustic transmitters with respect to spatiotemporal distribution or swimming depth during a $10 \mathrm{wk}$ period after simulated escape incidents. The tagged cod immediately descended to average depths $<20 \mathrm{~m}$, and subsequently were most frequently observed along the shore. A substantial proportion of the farmed cod released at the cod farm left within the first week, while cod released at a nearby mussel farm were attracted to the cod farm. Beyond Week 2, the fish detected at the cod farm consisted of approximately similar proportions of fish released at either the mussel or cod farm. One third of the tagged cod was recaptured in local smallscale commercial and recreational fisheries during the first $3 \mathrm{wk}$ after release. Thus, our results indicate that organised recapture fishery is a realistic option for reducing possible ecological and genetic impacts of escaped farmed cod. Such fishery must, however, be initiated as soon as possible after an escape incident and there is a need for development of a methodology for rapid detection and efficient recapture of escapees.
\end{abstract}

KEY WORDS: Atlantic cod $\cdot$ Gadus morhua $\cdot$ Aquaculture $\cdot$ Fish escape $\cdot$ Recapture Resale or republication not permitted without written consent of the publisher

\section{INTRODUCTION}

Farming of Atlantic cod Gadus morhua L. is a growing industry and $13500 \mathrm{t}$ of cod was produced in Norway in 2008 (Lassen 2009). Knowledge about ecological and genetic impacts of cod farming is still sparse, but recent research suggests that farmed cod are more likely to escape from marine net pen farms than Atlantic salmon Salmo salar L. (Moe et al. 2007). Between 2004 and 2008, a total of 912000 farmed cod escaped in Norway (Norwegian Directorate of Fisheries 2009) On average this corresponds to $1.1 \%$ of the number of fish in the farms at the end of each year (data from the Norwegian Directorate of Fisheries).
Moreover, from 2000 to 2005 up to $6 \%$ of the yearly farmed stock was estimated to escape (Moe et al. 2007). The proportion of cod escaping from farms is therefore higher than for salmon farming, where, at the end of each year, on average $0.2 \%$ of the number of fish in the farms was reported to escape from 2004 to 2009 (data from the Norwegian Directorate of Fisheries). The high escape risk of farmed cod is related to several factors; cod tend to bite holes in the net pen walls, they exhibit a swim pattern in the cages that involves a higher probability for finding holes in the net, and the technological and operational principles for cod farming in sea cages are principally developed for salmon and not for cod (Moe et al. 2007, Hansen et 
al. 2008). In addition, genetic and other factors like hunger level, stocking density and environmental variation might affect the escape likelihood of cod. It has, for example, been shown that the 2 genotypes Norwegian coastal cod (NCC) and north-east Arctic cod (NEAC) exhibit a movement pattern within rearing tanks that might involve higher escape risk (Hansen et al. 2008).

Even though little is known about any effect escaped farmed cod have on wild cod populations, the potential for negative ecological consequences seems to be significant (Bekkevold et al. 2006). It has been shown that escaped farmed cod are present in spawning areas for wild cod during the spawning season and that wild and escaped cod are likely to interbreed (Uglem et al. 2008, Meager et al. 2009). Farmed cod are also capable of producing viable cod larvae within sea cages, which subsequently mix with larvae from wild cod in the areas around cod farms (Jørstad et al. 2008). Thus, cod farming may result in unfavourable genetic changes in wild cod populations in the same way as is predicted for Atlantic salmon (Hindar et al. 2006). Furthermore, escaped farmed cod may transmit pathogens to wild populations (Øines et al. 2006) and increase predation pressure on wild salmon smolt (Brooking et al. 2006) and other fish species. Prevention of escape through improvement of farming husbandry and technology, as well as implementation of efficient recapture programmes, will therefore be important for developing a sustainable cod farming industry. The potential for breeding cod strains with innate behavioural patterns that involve reduced risk of escape or increased likelihood of recapture after escape should also be examined. In this context, extended knowledge about spatiotemporal dispersal of escaped cod originating from genetically differing sub-groups is important for improving recapture efficiency, predicting ecosystem effects and evaluating the practicability for selective breeding of cod strains with low escape risk.

In the present study, we examined the variation in movements of adult NCC and NEAC, cultured in a 'common garden' setting, i.e. under identical conditions, after simulated escape incidents. It is reasonable to assume that behavioural differences exist between these 2 cod groups since their life history differs in several ways (Fevolden \& Pogson 1997, Robichaud \& Rose 2004). For instance, NEAC migrate from feeding areas in the Barents Sea to spawning areas close to the coast (Hylen 1964, Bergstad et al. 1987, ICES 1994), while NCC have shorter feeding migrations and spawn in fjords and coastal areas (Rollefsen 1954, Jakobsen 1987, Godø 1995). To evaluate the feasibility of recapturing escaped cod and if escapees are attracted to fish farms, we released tagged cod both at a cod farm and at a nearby mussel farm.

\section{MATERIALS AND METHODS}

Study area. The study was carried out in Balsfjord $\left(69^{\circ} 22^{\prime} \mathrm{N}, 19^{\circ} 20^{\prime} \mathrm{E}\right)$ in Troms, northern Norway (Fig. 1). Balsfjord is a $57 \mathrm{~km}$ long single basin fjord with an average width of $\sim 3.5 \mathrm{~km}$, an area of $240 \mathrm{~km}^{2}$ and a maximum depth of $195 \mathrm{~m}$ (Eilertsen et al. 1981). The fjord is separated from the surrounding coastal waters and sounds by 3 shallow sills (9 to $30 \mathrm{~m}$ sill depths). Balsfjord is a cold-water fjord with temperatures from 1 to $7^{\circ} \mathrm{C}$ during most of the year, but during summer the temperature may be as high as $13^{\circ} \mathrm{C}$ in the upper water layer. The pycnocline oscillates around $10 \mathrm{~m}$. The fjord has several spawning areas for local coastal cod, which are characterised by sexual maturation at low age (4 to $6 \mathrm{yr}$ ) and small body size (40 to $50 \mathrm{~cm}$ in length) (Jakobsen 1987, Berg \& Albert 2003). The fjord also contains Atlantic cod and blue mussel (Mytilus edulis L.) farms, as well as a small local commercial cod fishery. During the current study, 2 to 3 small boats (28 to 35 feet; ca. 8.5 to $10.7 \mathrm{~m}$ ) were operating in the fjord system, using mainly bottom nets. As the majority of the local cod fisheries take place during February to April, the fishing effort in the fjord was low during the study period.

History of fish. Farmed cod were obtained from the Norwegian national cod breeding programme (Delghandi et al. 2003). The fish were first-generation NCC

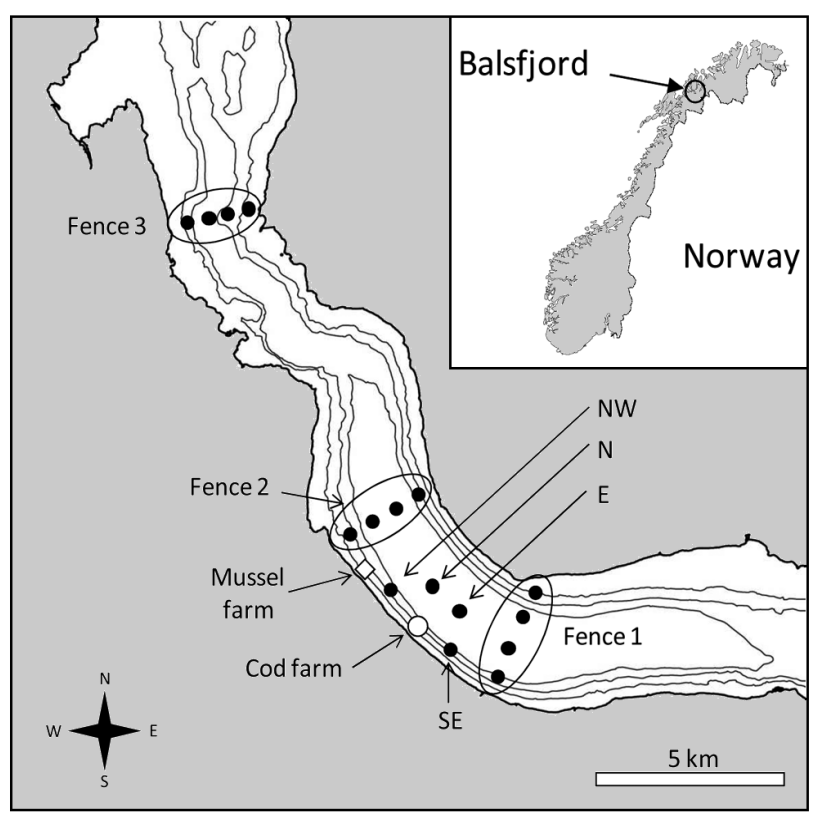

Fig. 1. Map of the study area in Balsfjord, Troms, northern Norway, with $(\bullet)$ receiver locations. Additionally, 1 receiver each (not shown) was positioned at the cod and the mussel farm. The 9 zones used in analyses of spatiotemporal distribution of the tagged cod are indicated with arrows and ellipses encircling the receivers. Positions of receivers around cod farm: $\mathrm{SE}=$ south-east, $\mathrm{E}=$ east, $\mathrm{N}=$ north, $\mathrm{NW}=$ north-west 
or NEAC. These 2 sub-groups can be separated on basis of variation in the 2 main alleles of the Pan I nuclear locus, Pan IA and Pan IB, which are predominant among NCC and NEAC, respectively (Fevolden \& Pogson 1997). The farmed cod were hatched during spring 2003 and were transferred to sea cages in Grøtsund, located $80 \mathrm{~km}$ from the field site in Balsfjord, during February 2004. The sub-groups were cultured in an identical way in the same sea cage, since they were a part of a breeding programme aimed at selection of cod strains with optimal properties for farming (Delghandi et al. 2003, Kettunen et al. 2007). The fish were tagged with passive integrated transponder (PIT) tags before they were transferred to common ongrowing tanks and later sea cages to allow individual identification. Three weeks before tagging with acoustic transmitters (see next paragraph) the farmed cod were transported from the sea cages in Grøtsund $\left(69^{\circ} 47^{\prime} \mathrm{N}, 19^{\circ} 09^{\prime} \mathrm{E}\right)$ to the field site in Balsfjord (Fig. 1) in a transportation tank (800 l volume) with water circulation placed onboard a boat. The cod were kept in a small storage pen (20 m circumference, $5 \mathrm{~m}$ depth) located between the cod farm and the mussel farm and later were released at either of these farms. The fish were fed in a similar manner as the fish in the cod farm until tagging. There was no mortality during or within the 3 wk after transport.

The cod were divided into 2 groups (Table 1) that subsequently were released at the cod farm ( $\mathrm{n}=24$; 12 NCC and 12 NEAC) and the nearby mussel farm ( $\mathrm{n}=21 ; 11 \mathrm{NCC}$ and $10 \mathrm{NEAC}$ ). The cod released at the cod farm were tagged with acoustic transmitters on 26 September 2007 and released on 28 September 2007. The cod released at the mussel farm were tagged 2 d later (28 September 2007) and treated in the same way as the cod released at the cod farm before they were released on 30 September 2007. Both groups were released during high tide.

Tagging. Immediately before tagging with acoustic transmitters, the fish (Table 1) were collected from the storage pen using a hand net. The cod were then anaesthetised by immersion in an aqueous solution of metacaine (Norsk medisinaldepot, $0.5 \mathrm{~g} \mathrm{l}^{-1}$; mean immersion period 3:07 $\mathrm{min}, \mathrm{SD}$ 0:13 $\mathrm{min}$; temperature in

Table 1. Gadus morhua. Length and weight of the tagged fish. NCC: Norwegian coastal cod, NEAC: north-east Arctic cod

\begin{tabular}{|c|c|c|c|c|c|c|c|}
\hline \multirow{2}{*}{$\begin{array}{l}\text { Release } \\
\text { location }\end{array}$} & \multirow[b]{2}{*}{ Release date } & \multirow[b]{2}{*}{ Genotype } & \multirow[b]{2}{*}{$\mathrm{n}$} & \multicolumn{2}{|c|}{ Length $(\mathrm{cm})$} & \multicolumn{2}{|c|}{ Weight (g) } \\
\hline & & & & Mean & $\mathrm{SD}$ & Mean & $\mathrm{SD}$ \\
\hline Cod farm & 28 Sep 2007 & $\mathrm{NCC}$ & 12 & 68.1 & 4.8 & 3791 & 986 \\
\hline Cod farm & 28 Sep 2007 & NEAC & 12 & 71.4 & 4.3 & 3897 & 689 \\
\hline Mussel farm & 30 Sep 2007 & $\mathrm{NCC}$ & 11 & 68.2 & 4.9 & 3919 & 731 \\
\hline Mussel farm & 30 Sep 2007 & NEAC & 10 & 71.9 & 3.8 & 4463 & 543 \\
\hline
\end{tabular}

solution: 8 to $10^{\circ} \mathrm{C}$ ) and placed ventral side up onto a V-shaped surgical table. An incision $(\sim 1.5 \mathrm{~cm})$ was made on the ventral surface posterior to the pelvic girdle using a scalpel. The coded transmitter (Vemco, model V13P-1L-R256, $13 \times 45 \mathrm{~mm}$, weight in water: $6 \mathrm{~g}$, frequency: $69 \mathrm{kHz}$, random pulse interval between 60 and $180 \mathrm{~s}$ ) was inserted through the incision and pushed into the body cavity in front of the pelvic girdle.

The incision was closed with 2 or 3 independent silk sutures (2/0, Ethicon). The fish were regularly sprayed with water during the surgery (mean \pm SD handling time 2:54 \pm 0:17 min, mean recovery time 3:25 \pm 1:19 min). Prior to each incision the surgical equipment was rinsed with $70 \%$ ethanol and allowed to dry. In addition, the fish were marked with an external T-bar anchor tag (Floy Tag) to enable individual identification in the event of recapture. After surgery, the tagged fish were allowed to recover for $2 \mathrm{~d}$ in a storage pen (20 m circumference, $5 \mathrm{~m}$ depth) located at the release site before they were released by slowly lowering one side of the net in the storage pen. No abnormal swimming patterns were observed immediately after the fish left the pen. All handling and tagging was conducted according to the Norwegian regulations on treatment and welfare of animals.

Configuration of the receiver array. The movements and distribution of the tagged fish was recorded using 16 individual acoustic receivers (Vemco, model VR2) deployed on anchored ropes at 7 different zones throughout the fjord system and 2 receivers positioned at the cod and mussel farm (Fig. 1). The depth at the receiver sites varied between 40 and $190 \mathrm{~m}$. Typically, the receivers were attached to the ropes at approximately half the distance to the bottom, except for the receivers deployed at the cod farm, which were suspended $10 \mathrm{~m}$ below the water surface. The average distance between receivers positioned in fences across the fjord was $500 \mathrm{~m}$. The detection range of the receivers at the cod and the mussel farm was restricted by attaching a waterproof conical plastic cap filled with air over the hydrophone (Uglem et al. 2008). This was done to record the presence of tagged cod in the immediate vicinity of the farms only. All receivers recorded the transmitter identification code, and date and time of detection when a tagged fish was within the receiver range. The detection range of the transmitters was determined by carrying out a series of range tests, where both the depth of the receiver and the transmitter were varied between $1 \mathrm{~m}$ and $90 \mathrm{~m}$ (Uglem et al. 2008). These tests showed that maximum detection range of the unrestricted receivers was between 600 and $700 \mathrm{~m}$ in radius, irrespective of receiver 
and transmitter depth, while maximum range of the restricted receivers at the cod and the mussel farm varied between 150 and $200 \mathrm{~m}$ in radius.

Data analyses. The data from the receiver array were pooled into 9 separate zones to represent the overall movement pattern of the fish after escape. The zones consisted of 3 fences with 4 receivers and 6 sites with single receivers (Fig. 1). Detection of a fish by at least one of the receivers within the different zones was defined as presence within the zone. In addition, the receivers in zones Fence 1 and Fence 2 were further divided into near-shore $(\mathrm{n}=4)$ and off-shore $(\mathrm{n}=4)$ receivers to evaluate the dispersal pattern of the tagged cod in relation to distance to the shore. The receivers occasionally recorded acoustic noise that was interpreted as a single reception of simply a transmitter ID code. To exclude false signals generated by environmental noise, single detections within $1 \mathrm{~h}$ were considered as erroneous, unless there was a clear indication that the detection was valid (frequent detection during the same day and also by nearby receivers). Fish that were detected in sequence in the Fences 2 and 3 zones, and then never again in the Fence 2 zone, were defined as 'departed' from the area inside of Fence 2. Fish that were not defined as 'departed' but that were not detected by any receiver. To be able to compare the 2 release groups, the date of release was defined as Day 0 for each group to standardize the data sets. Statistical analyses of variation in spatial distribution or swimming depth between the 2 release groups (at cod or mussel farm) or genotypes (NCC or NEAC) were carried out with data from within 2 wk after release including the date of recapture. We chose this 2 wk period as observed high recapture rates and rapid dispersal from release location considerably diminished sample sizes after Week 2 . To analyse variation in swimming depth between NCC and NEAC, data from the receivers in Fences 1 and 2 was used as these receivers were located at least $3 \mathrm{~km}$ away from the farm. Thus, the swimming depths at these locations could be assumed to be independent of fish farm structures and availability of waste fish feed. In those cases where tagged fish were recaptured within $2 \mathrm{wk}$ after release, the date of capture was taken into account in the statistical analyses. The data was analysed using the statistical software SPSS (version 16.0, SPSS) and R (version 2.9.0, R Project). The respective test type is specified in the 'Results' section and the significance level was established at $\mathrm{p}<0.05$.

\section{RESULTS}

The number of fish detected at the cod farm decreased rapidly after release at this farm (Fig. 2).

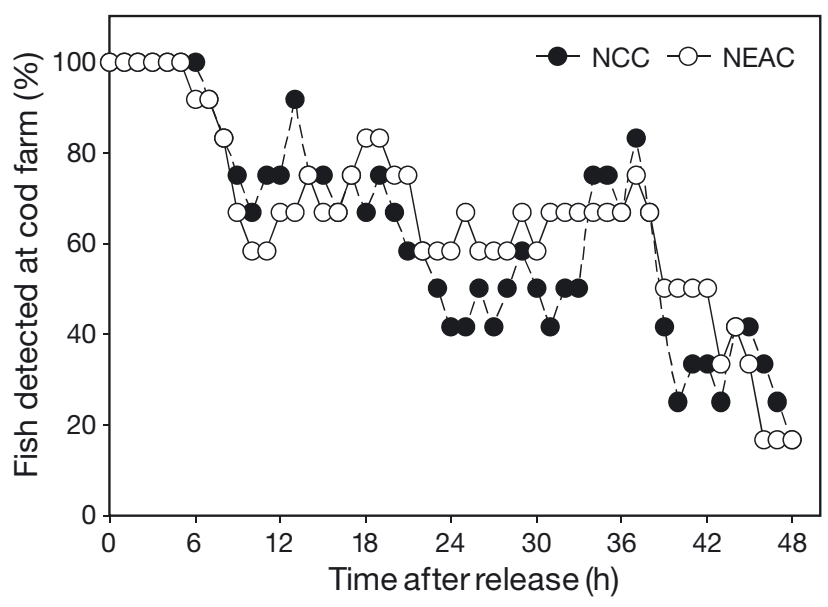

Fig. 2. Gadus morhua. Proportions of fish detected every hour in close proximity of the cod farm within $2 \mathrm{~d}$ after release at this farm. $(\bullet)$ Norwegian coastal cod (NCC), (O) north-east Arctic cod (NEAC)

There were no differences between NCC and NEAC with respect to the number of fish still being present at the farm $24 \mathrm{~h}$ (Fisher exact test, $\mathrm{p}=0.23$ ) and $48 \mathrm{~h}$ (Fisher exact test, $\mathrm{p}=0.41$ ) after release. Furthermore, there was no difference between NCC and NEAC with respect to when they left the farm for the first time (Survival analysis, log-rank, nonparametric test; $\mathrm{df}=1$, $\left.\chi^{2}=0.2, p=0.66\right)$. During the first week after release at the cod farm, tagged fish were observed in almost all receiver zones (Fig. 3). During the following $9 \mathrm{wk}$, the fish were continuously detected throughout the fjord, but there were no apparent or major variation in dispersal patterns between NCC and NEAC (Fig. 3).

The number of fish released at the cod farm that were detected by the 2 receivers located close to the shore around the farm (NW and SE in Fig. 3), was approximately twice the number detected by the 2 other receivers positioned around the farm ( $\mathrm{N}$ and $\mathrm{E}$ in Fig. 3, Fig. 4A). Furthermore, 21 (87.5\%) of the fish released at the cod farm were first detected by the NW or SE receivers (Fig. 4B). NCC and NEAC released at the cod farm did not differ with respect to the time of first detection (Mann-Whitney $U$-tests, $-1.11<Z<$ $-0.43,0.27<\mathrm{p}<0.67)$ or by which of the 4 receivers (SE, N, E, NW) surrounding the cod farm they were first detected (Fisher exact test, $\mathrm{p}=0.16$ ).

Fish from both releases (cod and mussel farm) were detected more frequently by the 4 receivers located near-shore in zones Fence 1 and Fence 2 during the first $2 \mathrm{wk}$ after release compared to the 4 receivers located off-shore (Table 2); paired $t$-test, $t=6.77, \mathrm{p}<0.001$ ). Fish released at the mussel farm were detected more often close to the shore than fish released at the cod farm, but there was no difference between NCC and NEAC with respect to the near-shore detection frequency (Fig. 4) 

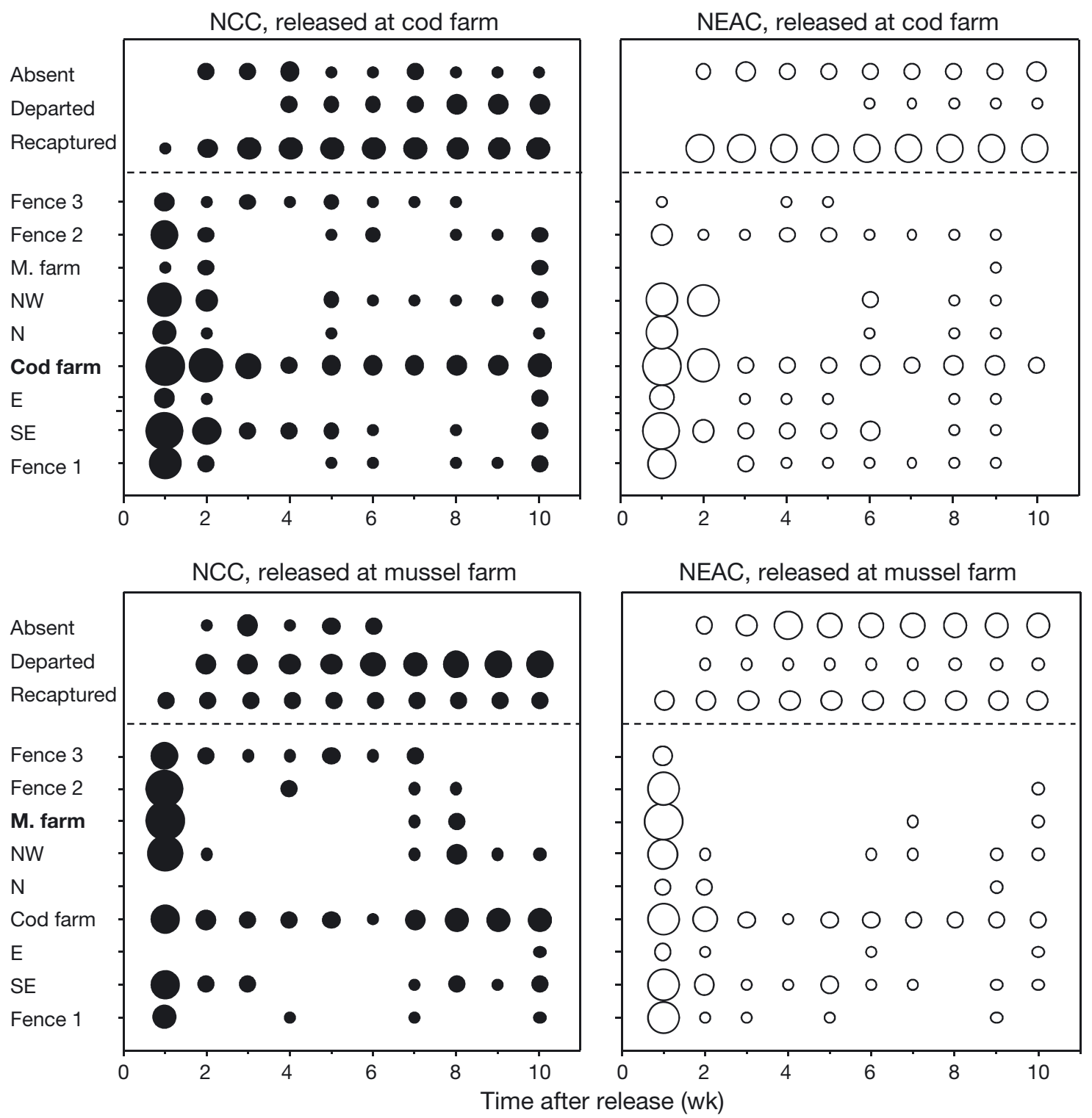

Fig. 3. Gadus morhua. Distribution of intentionally released (O) north-east Arctic cod (NEAC) and (@) Norwegian coastal cod (NCC) in Balsfjord. The size of the circles show the proportions of fish observed in various zones (see Fig. 1), as well as proportions of fish defined as having departed from the area inside of Fence 2 (departed), fish not defined as departed and not recorded within any zone (absent) and fish recaptured following release (recaptured). The smallest circles represent a proportion that corresponds to one single fish, while the largest circles represent all fish of a release group. The proportions of fish detected in various zones do not sum up to the total amount, as a fish could stay within several zones during the same week. The release farm is indicated with bold text on the $y$-axis. M. farm: Mussel farm. Positions of receivers around cod farm: $\mathrm{SE}=$ south-east, $\mathrm{E}=$ east, $\mathrm{N}=$ north, NW = north-west

(Univariate generalized linear model [GLM] with Release batch and Cod genotype as fixed factors; Release batch: $F=5.06, \mathrm{p}=0.03$, Cod genotype: $F=0.06, \mathrm{p}=0.81$, Interaction: $F=2.29, \mathrm{p}=0.14$ ). The detection rate in the areas covered by the receivers located off-shore in zones Fence 1 and 2, was not associated with cod genotype or release site (Table 2) (Univariate GLM with release batch and cod genotype as fixed factors; Release batch: $F=1.85, \mathrm{p}=0.18$, Cod genotype: $F=2.89, \mathrm{p}=0.10$, Interaction: $F=1.01, \mathrm{p}=0.32$ ).
Immediately after release at the cod farm most of the fish dived to depths between 20 and $60 \mathrm{~m}$ (Fig. 5). During the first $48 \mathrm{~h}$ after release, the average swimming depths of these fish varied between 22 and $50 \mathrm{~m}$. The average swimming depths of NCC and NEAC differed at 7 to $18 \mathrm{~h}$ after release, with NCC being detected at shallower waters than NEAC (Fig. 5) (Mann-Whitney $U$-tests; at $7-12 \mathrm{~h}: Z=-2.75, \mathrm{p}=0.006$; at $13-18 \mathrm{~h}: Z=$ $-2.24, p=0.025)$. The variation in average swimming depths in zones Fence 1 and 2 during the first $2 \mathrm{wk}$ 


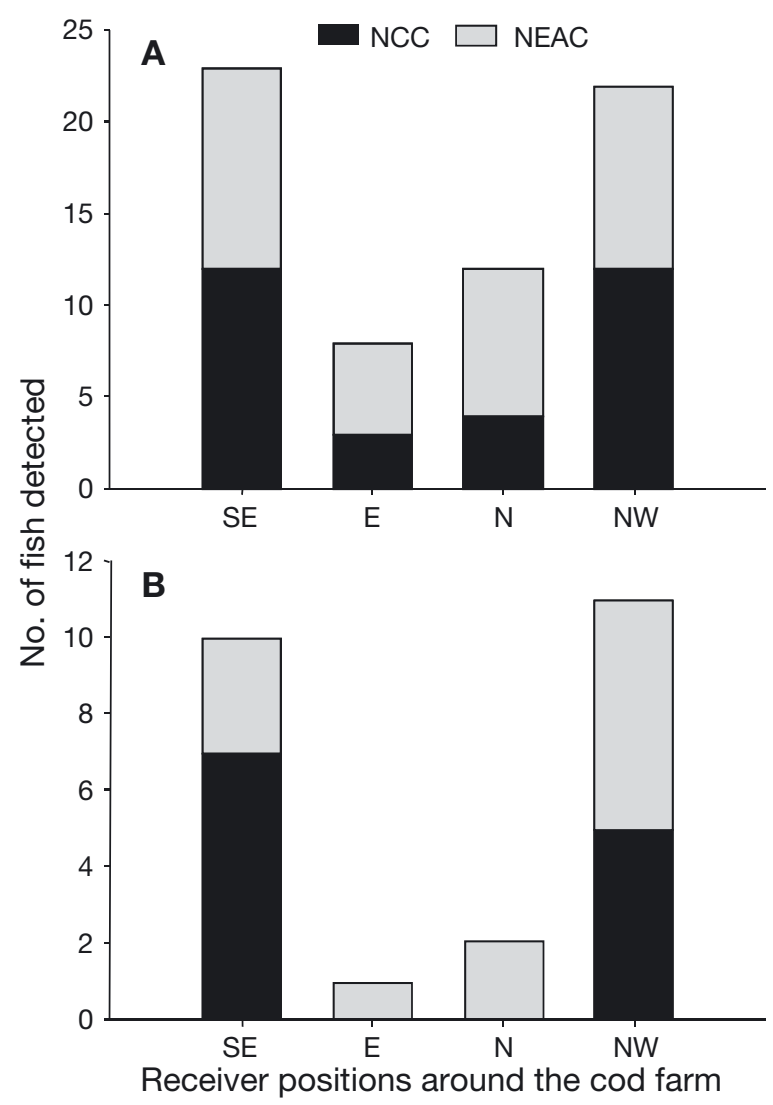

Fig. 4. Gadus morhua. Numbers of fish released at the cod farm that were (A) detected within $2 \mathrm{wk}$ after release or (B) first detected after release by the 4 receivers positioned around the cod farm. NCC: Norwegian coastal cod, NEAC: north-east Arctic cod. Positions of receivers around cod farm:

$\mathrm{SE}=$ south-east, $\mathrm{E}=$ east, $\mathrm{N}=$ north, $\mathrm{NW}=$ north-west

after release was not associated with cod genotype (NCC or NEAC) or release batch (Table 3) (Univariate GLM with Release batch and Cod genotype as fixed factors, Release batch: $F=0.02, \mathrm{p}=0.89$, Cod genotype: $F=0.25, \mathrm{p}=0.62$, Interaction: $F=1.23, \mathrm{p}=0.28$ ).

There was no difference between NCC and NEAC released at the mussel farm with respect to residence at this farm during the first $6 \mathrm{~h}$ after release (Fisher exact tests, $0.34<\mathrm{p}>0.19$ ). Beyond $6 \mathrm{~h}$ after release, the number of detections at the mussel farm was too low to allow statistical analyses, and NCC and NEAC were pooled to test if fish released at the mussel farm were attracted to the cod farm. Even on the very day of release, 8 out of 21 fish released at the mussel farm were also detected at the cod farm (Fig. 6). On Day 2, only 7 fish were detected at the mussel farm (Fig. 6). Between Days 2 and 6 after release, the number of fish released at the mussel farm and detected at the cod farm varied between 7 and 12 (Fig. 6). Beyond Week 2, the fish detected at the cod farm consisted of approximately similar proportions of fish originally released at
Table 2. Gadus morhua. Proportions of time $(\%, \pm 2 \mathrm{SE})$ within $2 \mathrm{wk}$ after release that the fish were detected by the 4 nearshore and 4 off-shore receivers in zones Fence 1 and 2. Recapture date was taken into account for the fish that were recaptured during this period. NCC: Norwegian coastal cod, NEAC: north-east Arctic cod

\begin{tabular}{|lcc|}
\hline & \multicolumn{2}{c|}{ Proportion of time (\%) } \\
Release location & NCC & NEAC \\
\hline Near-shore receivers & & \\
Cod farm & $18.7 \pm 5.5$ & $12.8 \pm 8.7$ \\
Mussel farm & $22.1 \pm 11.0$ & $30.3 \pm 11.9$ \\
Off-shore receivers & & \\
Cod farm & $3.5 \pm 3.7$ & $5.9 \pm 7.2$ \\
Mussel farm & $4.7 \pm 3.8$ & $14.2 \pm 11.7$ \\
\hline
\end{tabular}

either the mussel or cod farm (Fig. 3). On the other hand, only 3 out of 24 fish released at the cod farm were sporadically detected at the mussel farm.

During the 10 wk study period, 15 out of 45 tagged $\operatorname{cod}(33 \%)$ were recaptured by local fishermen. Ten of these originated from the fish released at the cod farm. A total of $9(60 \%)$ of the 15 recaptured fish were NEAC, but the proportions of recaptured fish did not differ between NCC and NEAC (Fisher exact test, $\mathrm{p}=$ 0.15). All recaptures occurred during the first $3 \mathrm{wk}$ after release at distances less than $15 \mathrm{~km}$ away from the cod farm.

\section{DISCUSSION}

There was no major difference between NCC and NEAC with respect to spatiotemporal distribution or swimming depth after a simulated escape incident

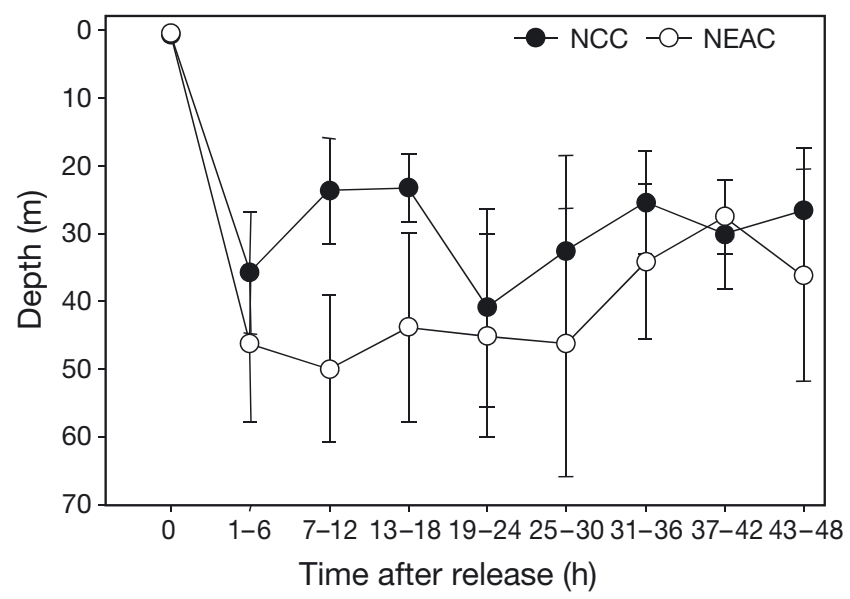

Fig. 5. Gadus morhua. Mean swimming depth ( $\pm 2 \mathrm{SE}$ ) of tagged fish released at the cod farm in relation to time after release. NCC: Norwegian coastal cod, NEAC: north-east Arctic cod 
Table 3. Gadus morhua. Mean swimming depths ( \pm 2 SE) in Fences 1 and 2 within 2 wk after release. NCC: Norwegian coastal cod, NEAC: north-east Arctic cod

\begin{tabular}{|llrllr|}
\cline { 2 - 3 } \cline { 5 - 6 } Release site & Depth $(\mathrm{m})$ & $\mathrm{n}$ & & Depth $(\mathrm{m})$ & $\mathrm{n}$ \\
\hline Cod farm & $31.8 \pm 5.8$ & 12 & & $47.4 \pm 11.6$ & 12 \\
Mussel farm & $36.7 \pm 17.9$ & 9 & & $31.7 \pm 7.5$ & 8 \\
\hline
\end{tabular}

from a commercial cod farm. One exception was that NEAC were detected at significantly greater depths than NCC 7 to $18 \mathrm{~h}$ after escape. This finding seems to contradict the general belief that NEAC have a more pelagic life style than NCC (e.g. Robichaud \& Rose 2004) and may simply be an artefact of low sample size and high variation. Alternatively, the variation in swimming depth might rather reflect the actual position of the fish since the water depth within the detection range of the receivers around the cod farm varied from $20 \mathrm{~m}$ near-shore to $80 \mathrm{~m}$ further out in the fjord. After release, most of the tagged cod descended rapidly from 0 to $3 \mathrm{~m}$ to depths $<20 \mathrm{~m}$. Thus, it is likely to assume that the cod were negatively buoyant after the descent, because the secretion rate of gas to the swim bladder for regulation of buoyancy would be too slow for allowing them to maintain neutral buoyancy (van der Kooij et al. 2007). Consequently, it is also reasonable to believe that the tagged fish stayed close to the bottom immediately after release and that receiver depths actually reflected the horizontal position of the fish around the cod farm.

Previous work has demonstrated that identically farmed adult NCC and NEAC differ with respect to disposition to pass through an opening in a net wall (Hansen et al. 2008). Also, Salvanes et al. (2004) docu-

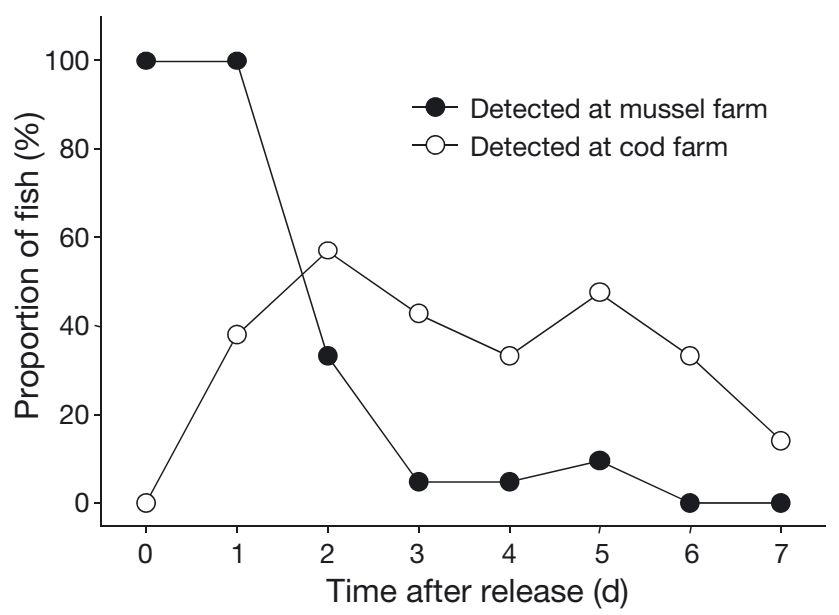

Fig. 6. Gadus morhua. Proportions of fish released at the mussel farm that were detected $(\bullet)$ at this farm or $(0)$ at the cod farm in relation to time, within $1 \mathrm{wk}$ after release mented behavioural differences between sub-groups of juvenile cod farmed in common-garden experiments. The lack of difference between NCC and NEAC in the present study might be related to several conditions. Firstly, the life histories of NCC and NEAC are predicted to differ over substantially longer time periods and at a larger geographical scale than covered by the present study (Rollefsen 1954, Hylen 1964, Bergstad et al. 1987, Jakobsen 1987, ICES 1994, Godø 1995). Moreover, the extent to which the behaviour of cultivated fish is modulated depends on the proportion of life spent in captivity (Fleming et al. 1996, 1997, Svåsand et al. 2001). As we studied adult farmed cod, the lack of behavioural differences between NCC and NEAC may be a result of a prolonged culture period. To conclusively rule out behavioural differences between NCC and NEAC following escape from sea cages, long-term studies, covering a larger geographical area, would be required.

The period the released cod stayed at the release farm before departing was somewhat longer in the present study compared to Uglem et al. (2008). In the present study 75 and $29 \%$ of the fish released at the farm were still present at this location during the second and third week, respectively. In Uglem et al. (2008) the corresponding average proportions of farmed fish present at the farm were $28 \%$ in Week 2 and $18 \%$ in Week 3 . Thus, approximately half of the fish delayed the departure by 1 wk in the current study compared to Uglem et al. (2008). The difference between the 2 studies could be due to them being carried out at different farms or other unknown factors, e.g. variation in weather or temperature conditions. Alternatively, the difference between the 2 studies could be related to the fact that the fish used in Uglem et al. (2008) originated from the cod farm used as release site in the present study, while the fish used in the present study originated from another farm (i.e. transplantation of fish). However, it would be reasonable to expect that transplanted cod would show less site fidelity than locally farmed cod (Windle \& Rose 2005). This was not the case as the transplanted fish in this study stayed at the farm for longer periods than reported for locally farmed cod (Uglem et al. 2008). Moreover, the fish used in the present study were allowed to acclimate to the area over at least $3 \mathrm{wk}$ before the study was initiated.

The behaviour of farmed fish after escape may in several ways influence the subsequent probability of capturing escapees in organised recapture fishery or in continuous surveillance fishery aimed at rapidly detecting escape incidents. Our results show that simulated escaped cod were observed most frequently by receivers positioned near-shore. Also the cod immediately dived to average depths $<20 \mathrm{~m}$ and a relatively 
high proportion of the fish left the cod farm within the first week after release there. All in all, our results indicate that organised recapture fishery in fjords resembling Balsfjord primarily should focus on areas close to the farm and the shoreline, with gear positioned close to the bottom at depths $<20 \mathrm{~m}$. In concurrence with Uglem et al. (2008), the results of the present study emphasise that recapture fishery should start as soon as possible after escape.

Almost all of the cod released at the mussel farm left the release location within the first $2 \mathrm{~d}$. Some of these fish were detected at the cod farm even at the release day. From the first week after release onwards, the fish that were detected at the cod farm consisted of approximately similar proportions of fish from both releases. This shows that simulated escaped cod are attracted to fish farms. Attraction of a range of marine fish species to farms due to the high abundance of waste fish feed is well documented (e.g. Dempster et al. 2009). Also, the physical structures constituted by floating cage farms can be attractive for wild marine fish as they provide shelter and concentrate natural prey organisms (Dempster \& Taquet 2004). Our results do, however, indicate that floating structures alone are not necessarily the prime reason for attraction of escaped fish to farms, since the fish released at the mussel farm did not seem to be attracted to these structures. The finding that released farmed cod are attracted to farms due to availability of waste fish feed suggests that commercial fish feed could be used for attracting escaped cod for recapture purposes. Whether or not this is a practical and realistic option has not been examined so far.

One third of the released fish were recaptured during the first $3 \mathrm{wk}$ after the simulated escape, despite a very modest local fishing effort. The high recapture rate of fish with acoustic tags corresponds with Uglem et al. (2008), who reported recapture rates of 28 to $52 \%$ in the same fjord in 2005 and 2006. Also, results from stock enhancement studies indicate that recapture of cod released as juveniles might be high, even with modest effort (up to 30\%; reviewed in Svåsand et al. 2001). These results suggest that a large scale and well-organised recapture of escaped cod would be a realistic option for reducing possible impacts of fish escapes from cod farms, as long as this fishery is initiated immediately after an escape incident. However, experiences from Norwegian cod culture indicate that many escape incidents remain undiscovered for days or even weeks, especially in cases when fish escaped through small openings in the net pen wall (I. Uglem \& P.A. Bjørn pers. observ.). In order to carry out organised and effective recapture fishery, there is thus a need for novel methodologies that enable rapid detection of escape from sea-cage fish farms.
Acknowledgements. We thank the crew at Lapponia Seafarms AS and Ronny Jakobsen from NOFIMA for their invaluable help during the course of the study. We also thank the local fishermen in Balsfjord for their assistance in returning tags from recaptured cod and for sharing their vast local knowledge with us. This research was funded by the Norwegian Research Council (project no. 165043), the strategic research project EcoMA and the EU-project PreventEscape (project no. 226885).

\section{LITERATURE CITED}

Bekkevold D, Hansen MM, Nielsen EE (2006) Genetic impact of gadoid culture on wild fish populations: predictions, lessons from salmonids, and possibilities for minimizing adverse effects. ICES J Mar Sci 63:198-208

> Berg E, Albert OT (2003) Cod in fjords and coastal waters of North Norway: distribution and variation in length and maturity at age. ICES J Mar Sci 60:787-797

Bergstad OA, Jørgensen T, Dragesund O (1987) Life history and ecology of the gadoid resources of the Barents Sea. Fish Res 5:119-161

Brooking P, Doucette G, Tinker S, Whoriskey FG (2006) Sonic tracking of wild cod, Gadus morhua, in an inshore region of the Bay of Fundy: a contribution to understanding the impact of cod farming for wild cod and endangered salmon populations. ICES J Mar Sci 63:1364-1371

> Delghandi M, Mortensen A, Westgaard JI (2003) Simultaneous analysis of six microsatellite markers in Atlantic cod (Gadus morhua): a novel multiplex assay system for use in selective breeding studies. Mar Biotechnol 5:141-148

- Dempster T, Taquet M (2004) Fish aggregation device (FAD) research: gaps in current knowledge and future directions for ecological studies. Rev Fish Biol Fish 14:21-42

Dempster T, Uglem I, Sanchez-Jerez P, Fernandez-Jover D, Bayle-Sempere J, Nilsen R, Bjørn PA (2009) Coastal salmon farms attract large and persistent aggregations of wild fish: an ecosystem effect. Mar Ecol Prog Ser 385: $1-14$

Eilertsen HC, Falk-Petersen S, Hopkins CCE, Tande KS (1981) Ecological investigation on the plankton community of Balsfjord, northern Norway: program for the project, study area, topography, and physical environment. Sarsia 66:25-34

Fevolden SE, Pogson GH (1997) Genetic divergence at the synaptophysin (Syn I) locus among Norwegian coastal and north-east Arctic populations of Atlantic cod. J Fish Biol 51:895-908

Fleming IA, Jonsson B, Gross MR, Lamberg A (1996) An experimental study of the reproductive behaviour and success of farmed and wild Atlantic salmon (Salmo salar). J Appl Ecol 33:893-905

> Fleming IA, Lamberg A, Jonsson B (1997) Effects of early experience on the reproductive performance of Atlantic salmon. Behav Ecol 8:470-480

Godø OR (1995) Transplantation-tagging experiments in preliminary studies of migration of cod off Norway. ICES J Mar Sci 52:955-962

Hansen LA, Dale T, Damsgård B, Uglem I, Aas K, Bjørn PA (2008) Escape-related behaviour of Atlantic cod, Gadus morhua L., in a simulated farm situation. Aquacult Res 40:26-34

Hindar K, Fleming IA, McGinnity P, Diserud O (2006) Genetic and ecological effects of salmon farming on wild salmon: modelling from experimental results. ICES J Mar Sci 63: $1234-1247$ 
Hylen A (1964) Coastal cod and skrei in the Lofoten area. Fiskeridir Ski Ser Havunders 13:27-42

ICES (International Council for the Exploration of the Sea) (1994) Spawning and life history information for North Atlantic cod stocks. ICES Coop Res Rep 205, Copenhagen

Jakobsen T (1987) Coastal cod in northern Norway. Fish Res 5:223-234

Jørstad KE, van der Meeren $T$, Paulsen OI, Thomsen $T$, Thorsen A, Svåsand T (2008) 'Escapes' of eggs from farmed cod spawning in net pens: recruitment to wild stocks. Rev Fish Sci 16:285-295

Kettunen A, Serenius T, Fjalestad KT (2007) Three statistical approaches for genetic analysis of disease resistance to vibriosis in Atlantic cod (Gadus morhua L.). J Anim Sci 85: 305-313

Lassen T (2009) Produksjon av torsk og kveite i 2008. Kyst og havbruk 2009 3, Havforskningsinstituttet, Bergen, p 131-132

Meager JJ, Skjæraasen JE, Fernö A, Karlsen Ø, Løkkeborg S, Michalsen K, Utskot SO (2009) Vertical dynamics and reproductive behaviour of farmed and wild Atlantic cod Gadus morhua. Mar Ecol Prog Ser 389: 233-243

Moe H, Dempster T, Sunde LM, Winther U, Fredheim A (2007) Technological solutions and operational measures to prevent escapes of Atlantic cod (Gadus morhua) from sea cages. Aquacult Res 38:91-99

Norwegian Directorate of Fisheries (2009) Escape data of 2006-2008. Available at: www.fiskeridir.no/statistikk/

Editorial responsibility: Tim Dempster,

Trondheim, Norway akvakultur/statistikk-for-akvakultur/torsk (accessed 22 Dec 2009)

Øines Ø, Simonsen JH, Knutsen JA, Heuch PA (2006) Host preference of adult Caligus elongatus Nordmann in the laboratory and its implications for Atlantic cod aquaculture. J Fish Dis 29:167-174

Robichaud D, Rose GA (2004) Migratory behaviour and range in Atlantic cod: inference from a century of tagging. Fish Fish 5:185-214

Rollefsen G (1954) Observations on the cod and cod fisheries of Lofoten. Rapp P-V Reùn Cons Int Explor Mer 136:40-47

Salvanes AGV, Skjæraasen JE, Nilsen T (2004) Subpopulations of coastal cod with different behaviour and life-history strategies. Mar Ecol Prog Ser 267:241-251

Svåsand $T$, Kristiansen TS, Pedersen $T$, Salvanes AGV, Engelsen R, Nævdal G, Nødtvedt M (2001) The enhancement of cod stocks. Fish Fish 1:173-205

Uglem I, Bjørn PA, Dale T, Kerwath S and others (2008) Movements and spatiotemporal distribution of escaped farmed and local wild Atlantic cod (Gadus morhua L.). Aquacult Res 39:158-170

> van der Kooij J, Righton D, Strand E, Michalsen K and others (2007) Life under pressure: insights from electronic datastorage tags into cod swimbladder function. ICES J Mar Sci 64:1293-1301

Windle MJS, Rose GA (2005) Migration route familiarity and homing of transplanted Atlantic cod (Gadus morhua). Fish Res 75:193-199

Submitted: December 22, 2009; Accepted: April 7, 2010 Proofs received from author(s): April 20, 2010 